\title{
ANALISIS PENGARUH VOLUME TABUNG TERHADAP EFISIENSI POMPA HYDRAM PADA KOLAM BUDAYA IKAN
}

\author{
ALI ROSYDIN ${ }^{1}$ YAFID EFFENDI $^{2}$, \& MUHAMAD RAMDANI $^{3}$ \\ ${ }^{1,2,3}$ Program Studi Teknik Mesin, Fakultas Teknik, Universitas Muhammadiyah Tangerang \\ Jl. Perintis Kemerdekaan I/33 Cikokol-Tangerang \\ E-mail: rosyidinali90@gmail.com
}

\begin{abstract}
ABSTRAK
Penelitian ini bertujuan untuk mengenalkan Perkembangan teknologi dalam pemanfaatan air sebagai sumber energi saat ini untuk mengurangi biaya tambahan dan penggunaan energi listrik.. Salah satu teknologi yang memanfaatkan air sebagai sumber energi yaitu Hydram. Hydram merupakan jenis pompa yang tidak memerlukan tenaga dari listrik atau tidak menggunakan energi listrik maupun dari motor bakar. Sehingga tidak menjadi beban bagi masyarakat untuk membayar listrik.Tujuan dilakukannya penelitian ini adalah untuk mengetahui pengaruh diameter pipa terhadap volume tabung dan mengetahui efisiensi Hydram pada kolam budidaya ikan. observasi dalam penelitian ini adalah pengamatan terhadap komponen utama mesin itu sendiri maupun terhadap lingkungan yang berkaitan dengan penggunaan mesin ini nantinya.Untuk menghitung penggunan diameter pipa untuk tabung udara semakin tinggi dan semakin besar diemeter pipa hasil yang diperoleh adalah tingkat efsiensi terbesar pada ukuran diameter pipa 4 inch efisiensi 52,5\%, dan yang terendah 3 inch efisiensi $15 \%$.Penggunaan tabung udara memiliki pengaruh yang sangat signifikan terhadap efisiensi pompa. Efisiensi tertinggi diperoleh pada volume tabung 0,00390 m dengan nilai efisiensi $52,5 \%$ dan efisiensi terendah diperoleh pada volume tabung 0,00090 m dengan nilai $15 \%$.
\end{abstract}

Kata kunci: analisis pompa ram hidrolik, ukuran pipa, debit air, pembuangan limbah.

\begin{abstract}
This research aims to introduce technological developments in the use of water as a current energy source to reduce additional costs and use of electrical energy. One technology that utilizes water as an energy source is Hydram. Hydram is a type of pump that does not require power from electricity or does not use electrical energy or from a combustion motor. So it does not become a burden for people to pay for electricity. The purpose of this study was to find out the effect of pipe diameter on the volume of the tube and to find out the efficiency of Hydram in fish farming ponds. Observation in this study is an observation of the main components of the machine itself as well as to the environment related to the use of this machine later.To calculate the use of pipe diameter for air tubes the higher and larger the pipe diemeter obtained is the largest efficiency rate at the diameter of the pipe 4 inch efficiency $52,5 \%$, and the lowest 3 inch efficiency $15 \%$. The use of air tubes has a very significant influence on the efficiency of the pump. The highest efficiency is obtained at a tubes volume of $0.00390 \mathrm{~m}$ with an efficiency value of $52,5 \%$ and the lowest efficiency is obtained at a tube volume of $0.00090 \mathrm{~m}$
\end{abstract}

Keywords: hydraulic ram pump analysis, pipe size, water discharge, sewage discharge

\section{PENDAHULUAN}

Pada umumnya kondisi suatu lingkungan dipengaruhi oleh sumber daya alam yang terdapat pada daerah tersebut, termasuk kualitas sumber daya manusia yang memanfaatkan alam untuk kelangsungan hidup manusia. Di daerah - daerah perkotaan sangat dibutuhkan SDM - SDM yang unggul dalam membangun suatu wilayah yang mandiri dan berkembang.

Salah satu masalah nyata yang banyak dialami oleh masyarakat perkotaan yaitu kurangnya ketersediaan air untuk mencukupi kebutuhan sehari-hari dan penggunaan peralatan elektronik yang berlebihan. Penggunaan air untuk kebutuhan sehari - hari dalam menjamin kelangsungan hidup manusia, misalnya untuk kolam ikan, dan lain - lain.Dapat dilihat dari keuntungan Hydram ini, sangat cocok2 untuk mengatasi masalah-masalah yang dihadapi masyarakat dalam mengatasi kekurangan atau kesulitan air. Penggunaan ukuran diameter pipa juga dapat mempengaruhi volume tabung terhadap efisiensi pompa hydram pada kolam budidaya ikan.

Perkembangan teknologi dalam pemanfaatan air sebagaisumber energi saat ini untuk mengurangi biaya tambahan dan dan penggunaan energi 
listrik. Salah satu teknologi yang memanfaatkan air sebagai sumber energi yaitu Hydram. Hydram merupakan jenis pompa yang tidak memerlukan tenaga dari listrik atau tidak menggunakan energi listrik maupun dari motor bakar. Sehingga tidak menjadi beban bagi masyarakat untuk membayar listrik

\section{METODOLOGI PENELITIAN}

Metode dalam penelitian ini yang digunakan adalah metode obeservasi, yaitu Observasi merupakan salah satu metode pengumpulan data dengan cara mengamati atau meninjau secara cermat dan langsung di lokasi penelitian untuk mengetahui kondisi yang terjadi atau membuktikan kebenaran dari sebuah desain penelitian yang sedang dilakukan.

Pompa hydram dibuat dengan menggunakan peralatan-peralatan utama, antara lain mesin konvensional, alat perkakas, dan alat ukur. Adapun peralatan yang digunakan selama pembuatan alat penelitian ini adalah:

1. Gergaji Besi

Gergaji besi / hack saw adalah gergaji yang digunakan untuk memotong benda berbahan logam seperti besi. Disebut gergaji besi karena biasanya benda berbahan logam disebut besi. Selain logam, gergaji ini juga bisa digunakan untuk memotong bahan lain seperti pve dan juga kayu. Gergaji ini memiliki mata gergaji yang halus dan rapat. Seperti gergaji triplek / coping saw, mata gergaji ini juga bisa dilepas dan diganti apadila sudah tumpul. Bobot yang ringan juga jadi kelebihan dari gergaji ini. Pada proses pembuatan pompa hydram, gergaji besi digunakan untuk memotong pipa pvc penyambung, lihat Gambar 1 dan spesifikasipada gergaji besi dapat dilihat Tabel 1 .

\section{Tabel.1 Spesifikasi Gergaji Besi}

\begin{tabular}{|l|l|}
\hline Panjang & $48 \mathrm{~cm}$ \\
\hline Panjang Mata Gergaji & $31 \mathrm{~cm}$ \\
\hline Lebar & $12 \mathrm{~cm}$ \\
\hline Tebal & $2,4 \mathrm{~cm}$ \\
\hline Tebal Mata Gergaji & $0.5 \mathrm{~mm}$ \\
\hline
\end{tabular}

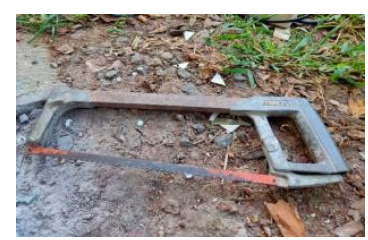

Gambar 1. Gergaji Besi

\section{Mesin Bor}

Mesin bor digunakan untuk melubangi dop pipa yang terdapat pada katup buang, lihat gambar 2.contoh spesifikasi pada mesin bordapat dilihat pada Tabel 2

Tabel.2 Spesifikasi Mesin Bor

\begin{tabular}{|l|l|}
\hline Ukuran & $\begin{array}{l}30 \mathrm{~cm} \times 15 \mathrm{~cm} \\
\text { x } 8 \mathrm{~cm}\end{array}$ \\
\hline Bobot & $2 \mathrm{~kg}$ \\
\hline $\begin{array}{l}\text { Sumber } \\
\text { listrik }\end{array}$ & Daya listrik AC \\
\hline $\begin{array}{l}\text { Voltase } \\
\text { Daya }\end{array}$ & $220 \mathrm{~V} \cdot 550 \mathrm{~W}$ \\
\hline $\begin{array}{l}\text { Kecepatan } \\
\text { putaran }\end{array}$ & $2.900 \mathrm{rpm}$ \\
\hline $\begin{array}{l}\text { Kapasitas } \\
\text { chuck }\end{array}$ & $10 \mathrm{~mm}$ \\
\hline $\begin{array}{l}\text { Fitur } \\
\text { tambahan }\end{array}$ & $\begin{array}{l}\text { Variasi } \\
\text { kecepatan, } \\
\text { reversible } \\
\text { (putaran } \\
\text { bolak- } \\
\text { balik) }\end{array}$ \\
\hline
\end{tabular}

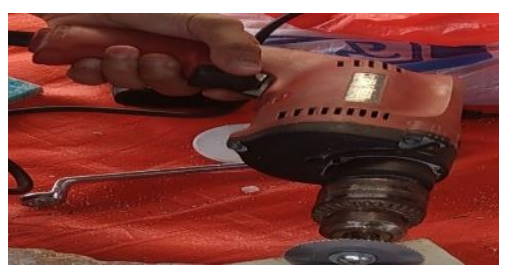

Gambar.2 Mesin Bor

\section{Kunci Ring}

Fungsi kunci ring untuk mengencangkan dan mengendurkan mur maupun baut,kunci ring yang di gunakan ukuran $13 \mathrm{~mm}$ lihat Gambar 3

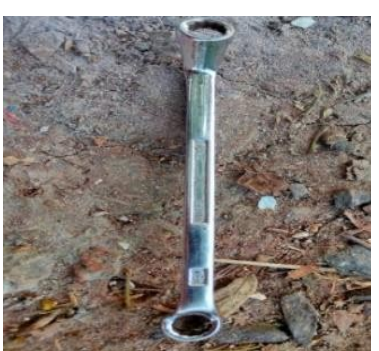

Gambar 3. Kunci Ring

\section{4. $\quad$ Obeng}

Obeng digunakan yaitu obeng plus sedangkan dalam bahasa inggris obeng plus memiliki nama Phillips screwdriver. Karena bentuknya tersebut, maka fungsi obeng plus adalah 
untuk mengendorkan atau mengencangkan sekrup yang bagian mata atau kepalanya juga berbentuk plus ataukembang,lihat Gambar 4.

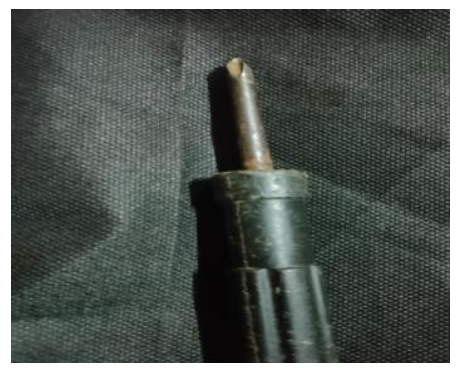

Gambar 4. Obeng

\section{Kunci inggris (adjustablespanner)}

Kunci inggris Adalah kunci untuk melepas atau memasang mur atau baut yang dapat disetel menyempit atau melebar menyesuaikan dengan ukuran mur atau bautnya. Spesifikasi Kunciinggris (adjustablespanner ) yang di gunakan bisa dilihat di Tabel 3 dan Gambar 5

\section{Tabel 3. Spesifikasi Kunci Inggris}

\begin{tabular}{|l|l|}
\hline $\begin{array}{l}\text { Panjang ukuran } \\
\text { kunci inggris }\end{array}$ & 24 inchi \\
\hline $\begin{array}{l}\text { Panjang kunci } \\
\text { inggris }\end{array}$ & $612 \mathrm{~mm}$ \\
\hline $\begin{array}{l}\text { Ukuran rahang } \\
\text { saat terbuka }\end{array}$ & $62 \mathrm{~mm}$ \\
\hline
\end{tabular}

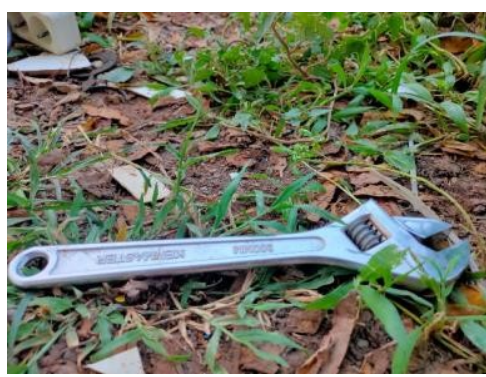

Gambar 5. Kunci Inggris

6. Gelas ukur

Gelas ukur digunakan untuk mengukur debit air yang keluar melalui waste valve dan delivery pipe. Gelas ukur yang digunakan berukuran 500 $\mathrm{ml}$.

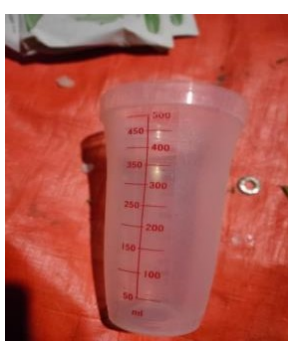

\section{Gambar 6. Gelas Ukur}

7. Solder

Solder berfungsi untuk melelehkan dan melubangi seal dan pipa ,solder lihat Gambar 7 dan contoh spesifikasi pada mesin solderdapat dilihat pada Tabel 4 .

Tabel 4. Spesifikasi Solder

\begin{tabular}{|l|l|}
\hline Model & TQ-66 \\
\hline Tegangan & $\begin{array}{l}220-240 \mathrm{~V} \quad \text { AC } \\
50 / 60 \mathrm{~Hz}\end{array}$ \\
\hline Daya & $\begin{array}{l}\text { Tinggi 200W / } \\
\text { Rendah }\end{array}$ \\
& $\begin{array}{l}\text { 0W(model 220- } \\
\text { 240V) }\end{array}$ \\
\hline $\begin{array}{l}\text { Resistansi } \\
\text { Isolasi }\end{array}$ & $\begin{array}{l}\text { Lebih dari 100M } \\
\text { (500V DC) }\end{array}$ \\
\hline $\begin{array}{l}\text { Panjang Kabel } \\
\text { Listrik }\end{array}$ & $1.5 \mathrm{~m}$ \\
\hline $\begin{array}{l}\text { Panjang tanpa } \\
\text { bushing kabel }\end{array}$ & $167 \mathrm{~mm}$ \\
\hline $\begin{array}{l}\text { Mata Solder } \\
\text { Goot }\end{array}$ & 40 Watt R-48SB( \\
Ujung Tajam)
\end{tabular}

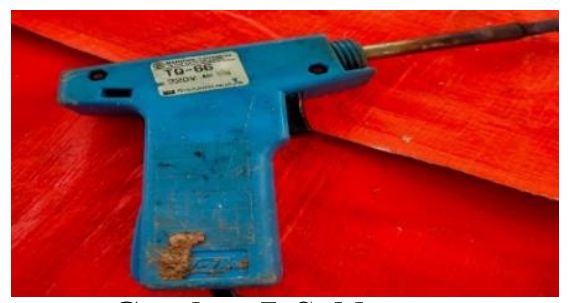

Gambar 7. Solder

8. Stick dan Glue Gun

Untuk merekatkan sambungan pipa dan seal pada saat di satukan lem jenis ini memiliki keunggulan lebih cepat kering. Glue gun dapat dilihat pada Gambar.8 dan contoh spesifikasi pada mesin solder dapat dilihat pada Tabel 5.

Tabel 5. Spesifikasi Stick dan Glue Gun

\begin{tabular}{|l|l|}
\hline $\begin{array}{l}\text { Jenis power } \\
\text { supply }\end{array}$ & kabel \\
\hline Ukuran & $13 \mathrm{~cm} \mathrm{x} \mathrm{11} \mathrm{cm}$ \\
\hline Daya & $20 \mathrm{~W}$ \\
\hline $\begin{array}{l}\text { Diameter } \\
\text { glue stick }\end{array}$ & $7 \mathrm{~mm}$ \\
\hline Frekuensi & $50-60 \mathrm{~Hz}$ \\
\hline
\end{tabular}




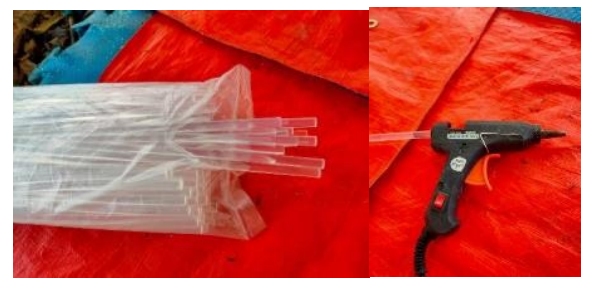

\section{Gambar 8. Stick dan Glue Gun}

9. Sealant Gun

Sealant digunakan untuk menutup ruang atau celah di antara dua material agar terhindar dari kebocoran air

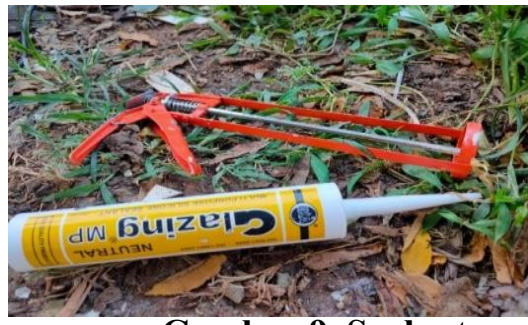

Gambar 9. Sealant

10. Salang air benang

Selang ini digunakan sebagai tempatair yang keluar dari pipaoutlet, lihat Gambar 10.

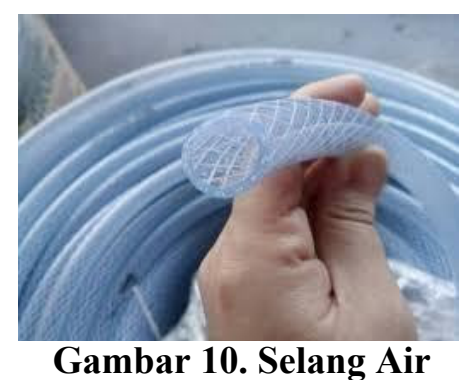

\section{Gerinda}

Gerinda

digunakan

untuk mengasah/memotong atau pun menggerusbenda kerja dengan tujuan atau kebutuhan tertentu. Gerinda dapat dilihat pada Gambar 11 dan contoh spesifikasi pada mesin gerinda dapat dilihat pada Tabel 6 .

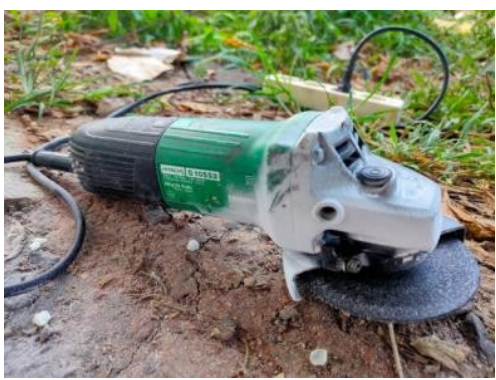

Gambar 11. Gerindra
Tabel 6. Spesifikasi Mesin Gerinda

\begin{tabular}{|l|l|}
\hline Merek & Hitachi G10SS2 \\
\hline Daya Listrik & $580 \mathrm{Watt}$ \\
\hline Kec.Tanpa beban & $11000 \mathrm{rpm}$ \\
\hline Ukuran Batu & 4 "100 mm \\
\hline Ukuran Spindle & M10×1,5 \\
\hline Berat & $1,6 \mathrm{~kg}$ \\
\hline Voltase & $220 \mathrm{~V} / 50 \mathrm{~Hz}$ \\
\hline Panjang & 260 \\
\hline
\end{tabular}

12.Ember

Ember pada proses pengujian pompa hydram berfungsi sebagai tempat sumber air masuk, lihat Gambar 12.

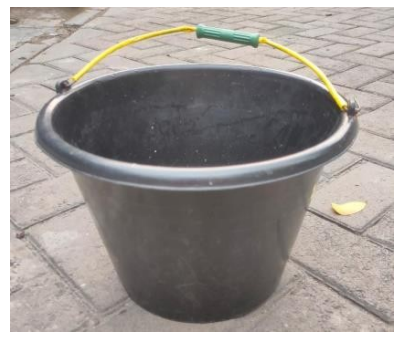

Gambar 12. Ember

13. Kompor portable

Kompor portable digunakan untuk memanaskan pipa-pipa agar tebentukukuran yang di inginkan

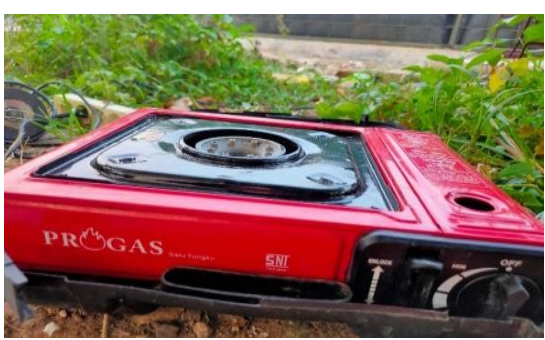

Gambar 13. Kompor portable

\section{Meteran}

Meteran digunakan untuk melakukan pengukuran terhadap bahan yang akan digunakan, lihat Gambar 14.

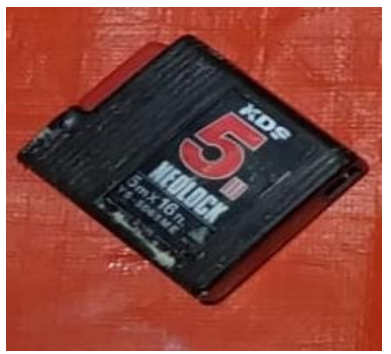

Gambar 14. Meteran 
Berdasarkan perencanaan bahan-bahan yang akan digunakan dalam pembuatan pompa hydram adalah:

\section{Pipa L PVC}

Pipa $\mathrm{L}$ yang digunakan untuk membelokkan air,pipa L yang digunakanberukuran $1 / 2$ inch yang terubuat dari bahan pvc seperti pada Gambar 15 .

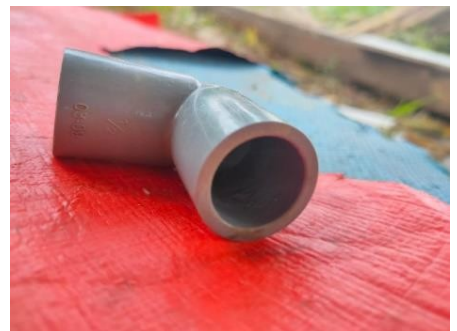

Gambar 15. Pipa L PVC

2. Pipa T PVC

Pipa $T$ yang digunakan untuk menghubungkan pipa penghantar dengan klep buang/tekan, serta tabung udara dengan pipa penyalur. Sambungan $\mathrm{T}$ yang di gunakan berjenis pvc seperti pada Gambar 16.

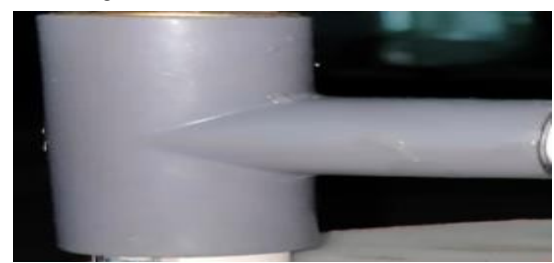

Gambar 16. Pipa T PVC

3. Pipa Socket

Pipa Socket yang digunakan dalam pembuatan pompa hydram berjumlah 2 per pompa, lihat Gambar 17.

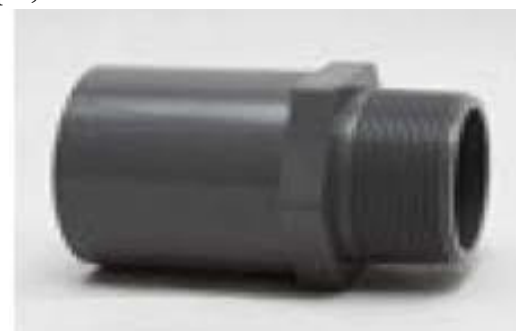

Gambar 17. Pipa Socket

4. Pipa Penyambung

Pipa penyambung berfungsi sebagai penyambung antara pipa yang satu dengan yang lainnya, lihat Gambar 18.

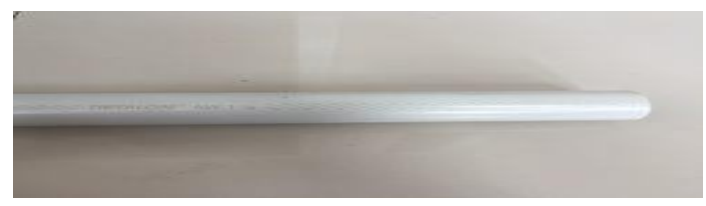

Gambar 18. Pipa Penyambung

5. Reducer Pipa

Reducer pipa dibutuhkan untuk transisi perubahan diameter ukuran pipa, lihat Gambar 19.

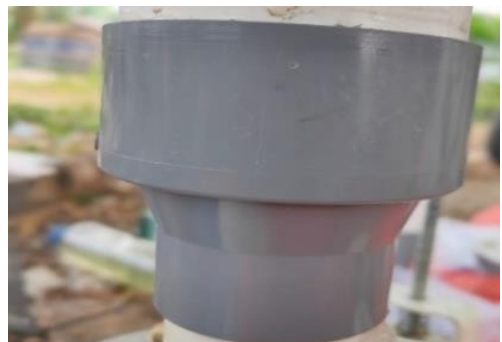

Gambar 19. Reducer Pipa

6. Dop Pipa PVC

Tutup pipa digunakan untuk menutup saluran pada ujung pipa PVC, lihat Gambar 20.

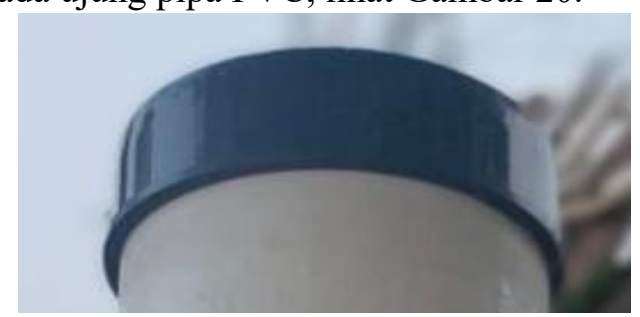

7. Klep Pipa

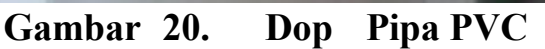

Klep pipa berfungsi sebagai penahan aliran air yang telah berada pada pipa agar tidak kembali turun kebawah,klep pipa yang terbuat dari karet ban dan pipa ukuran 4inch yang dibentuk menjadi lingkaran, klep pipa dapat lihat Gambar 21.

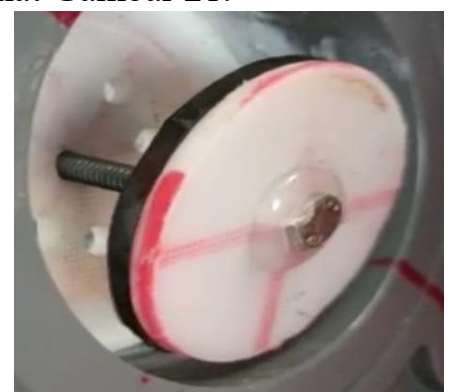

Gambar 21. Klep Pipa

8. Baut panjang

Baut panjang digunakan sebagai batang pada katub buang, lihat Gambar 22. 

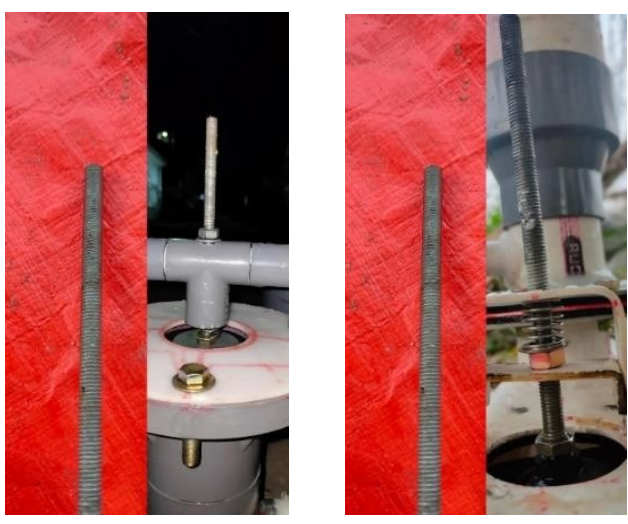

Gambar 22. Baut Panjang

\section{Ring Baut}

Ring baut pada pompa hydram difungsikan sebagai massa pemberat dan mendorong baut atau mur sebagai oengunci dapat dilohat Gambar 23.

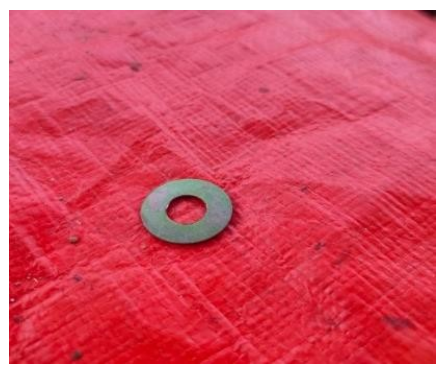

\section{Gambar 23. Ring Baut}

10.Mur

Mur berfungsi untuk mengencangkan baut pada benda satu dengan yang lainnya, lihat Gambar 24.

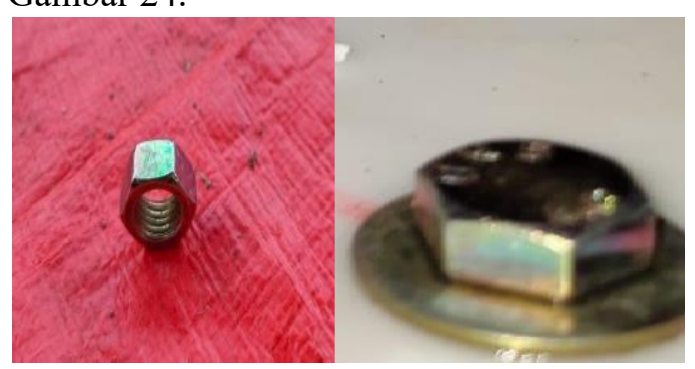

Gambar 24. Mur

11. Screw

Screw digunakan untuk memegang dan memasang beberapa objek, screw yang di gunakan beukuran 15 mlihat Gambar 25 .

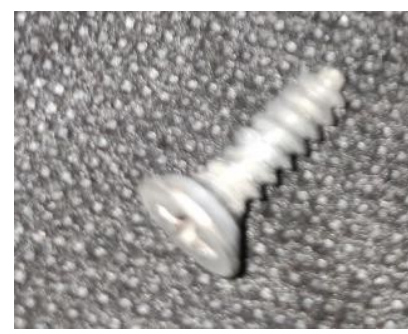

Gambar 25. Screw

\section{Flange}

Flange adalah suatu bagian dari pipa yang berfungsi sebagai penyambung pada pipa.Flange yang di gunakan ukuran 2,5 inch dan 3 inch. Flange dapat dilihat pada Gambar 26.

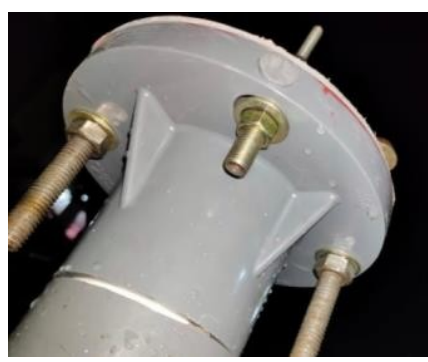

\section{Gambar 26. Flange}

\section{Talenan}

Talenan berfungsi untuk meratakan area flange agar tidak bocor dapat dilihat Gambar 27.

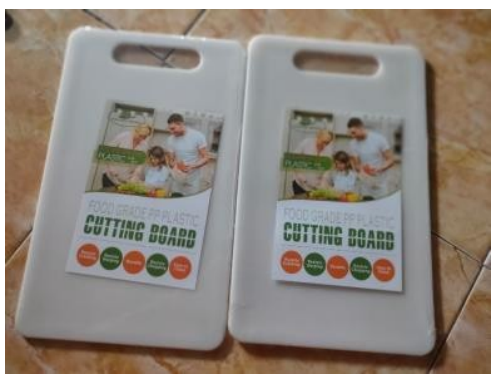

Gambar 27. Talenan

\section{Lem pipa PVC}

Lem pipa PVC berfungsi untuk merekatkan dan menyambungkan pipa PVC, lihat Gambar 28.

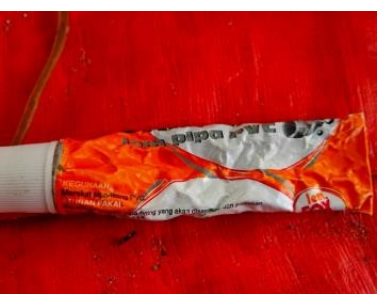

Gambar 28. Lem Pipa PVC 


\section{HASIL DAN PEMBAHASAN}

\subsection{Pengaruh Perbandingan Ukuran Pipa terhadap efisiensi Volume Tabung pada Pompa Hydram.}

Pompa Hydram merupakan pompa yang bekerja tanpa menggunakan energi listrik, namun dengan memanfaatkan energI dari aliran air itu sendiri untuk mengangkat sebagian airdari suatu sumber ketempat penampungan air yang tempatnya lebih tinggi. Dalam penggunaan pompa hidram terdapat beberapa komponen yang sangat mempengaruhi kinerja dari dari pompa tersebut diantaranya tabung udara dan pipa masukan.

Pada penelitian ini dilakukan, dengan melihat pengaruh volume tabung udara Adapun variabel tetap pada penelitian ini yaitu waktu selama 60 sekon tiap kali pengambilan data dan pipa keluaran dengan ketinggian 3 meter. Adapun komposisi pada penelitian dengan menggunakan variasi volume tabung dapatdilihat pada Tabel 7 .

Tabel 7. Variasi Volume Tabung

\begin{tabular}{|c|c|c|c|}
\hline jenis & $\begin{array}{l}\text { Tinggi } \\
\text { pipa }\end{array}$ & Konvers & Volume \\
\hline 3 inch & 20 & \multirow{3}{*}{$\begin{array}{l}\mathrm{Cm} \\
\mathrm{m}^{3}\end{array}$} & 0,0090 \\
\hline & 24 & & 0,00108 \\
\hline 4 inch & 48 & & 0,00390 \\
\hline
\end{tabular}

\subsection{Pengaruh Volume Tabung terhadap efisiensi Pompa Hydram}

Dalam penelitian ini menggunakan tabung udara dengan diameter 4 inci dengan volume yang berbeda-beda. Tingkat air yang digunakan berada pada posisi 0,5 meter dengan ketinggian 3 meter dari menghitung debit output. Parameter yang diamati adalah debit masuk, debit hasil dan debit limbah. Berdasarkan hasil pengujian yang telah dilakukan dengan menggunakan alat pompa hydram diperoleh data seperti pada Tabel 8.
Tabel 8. Pengaruh Volume Tabung terhadap Efisiensi Pompa Hydram

\begin{tabular}{|c|c|c|c|c|c|c|c|}
\hline $\begin{array}{l}\text { Volum } \\
\mathrm{e} \\
\text { tabun } \\
\mathrm{g} \quad(\mathrm{m} \\
)\end{array}$ & $\begin{array}{c}\mathrm{He} \\
\mathrm{ad} \\
\mathrm{mas} \\
\mathrm{u} \mathrm{k} \\
(\mathrm{m})\end{array}$ & $\begin{array}{l}\text { Hea } \\
d \\
\text { kelu } \\
\text { ar } \\
(\mathrm{m})\end{array}$ & $\begin{array}{c}\text { Debi } \\
t \text { air } \\
\text { pipa } \\
\text { mas } \\
\text { uk } \\
\left(\mathrm{m}^{3 / s} \mathrm{~s}\right. \\
)\end{array}$ & $\begin{array}{c}\text { Debit } \\
\text { hasil } \\
\left(\mathrm{m}^{3} / \mathrm{s}\right. \\
)\end{array}$ & $\begin{array}{l}\text { Deb } \\
\text { it } \\
\text { limba } \\
\text { h } \\
\left(\mathrm{m}^{3 /} /\right. \\
\mathrm{s})\end{array}$ & $\begin{array}{l}\text { Wak } \\
\text { tu } \\
\text { (s) }\end{array}$ & $\begin{array}{l}\text { Efisie } \\
\text { nsi } \\
(\%)\end{array}$ \\
\hline $\begin{array}{c}0,000 \\
90\end{array}$ & 0,5 & 3 & $\begin{array}{c}0,00 \\
62\end{array}$ & $\begin{array}{c}0,000 \\
4\end{array}$ & 0,004 & 60 & 15 \\
\hline $\begin{array}{c}0,001 \\
08\end{array}$ & 0,5 & 3 & $\begin{array}{c}0,00 \\
62\end{array}$ & $\begin{array}{c}0,000 \\
55\end{array}$ & 0,003 & 60 & 27,5 \\
\hline $\begin{array}{c}0,003 \\
90\end{array}$ & 0,5 & 3 & $\begin{array}{c}0,00 \\
62\end{array}$ & $\begin{array}{c}0,000 \\
7\end{array}$ & 0,002 & 60 & 52,5 \\
\hline
\end{tabular}

\section{KESIMPULAN}

Berdasarkan penelitian yang telah dilakukan dapat disimpulkan bahwa :

1. Untuk tingkat efisiensi terbesar dari penggunaan ukuran diameter pipa adalah tabung dengan ukuran 4 inch dan tingkat efisiensi terendah pada tabung pipa berukuran 3 inch.

2. Penggunaan tabung udara memiliki pengaruh yang sangat signifikan terhadap efisiensi pompa hydram karena tabung udara akan menekan air yang ada didalamnya sehingga akan lebih banyak terpompa keatas dimana dalam penelitian ini efisiensi tertinggi diperoleh pada volume tabung $0,00390 \mathrm{~m}$ dengan nilai efisiensi $52,5 \%$ dan efisiensi terendah diperoleh pada volume tabung $0,00090 \mathrm{~m}$ dengan nilai $15 \%$. 


\section{DAFTAR PUSTAKA}

Budiyanto. 2009. Pengaruh Tinggi dan Diameter inlet terhadap Kapasitas Pompa Hidram dengan Modal Simulasi Program Delphi. Malang: Jurnal Flywheel. Vol. 2,No.2.

Darma Surya, 2013. Rancang Bangun Pompa Hidraulik Ram (Hydram). Universitas Sumatera Utara. Medan.

Ginting andrea Sebastian, 2014. Analisa Pengaruh Variasi Volume Tabung Udara Dan Variasi Beban Katup Limbah Terhadap Performa Pompa Hydram. Departemen Tehnik Mesin, Fakultas Teknik, Universitas Sumatera Utara.

Nadya Yusri, Hasan Thalib.M, Subhan,Swary Wahyu Mahades, 2014. Pengujian Karakteristik Pompa Hydraulic Ram (Hydram) Menggunakan Tabung Udara 0,00455 $\mathrm{M}^{\wedge} 3$. Program Studi Teknik Industri, Universitas Samudra. Meurandeh - Langsa, Aceh.

Rahmat Dzikri, dkk. (2013). Pengaruh Variasi Tinggi Katup Limbah dan Jarak Antara Katup Terhadap Efisiensi Pompa Hidram. Jurnal, Program Studi Pengajaran Fisika, Institut Teknologi Bandung.

Suroso,Priyanto Dwi \& Krisandi Yordan, 2012. Pembuatan Dan Karakteristik Pompa Hydraulic Pada Ketinggian Sumber 1,6 Meter, STTN - Batan \& PT - Batan Yogyakarta.

San Gan Shu, Santoso Gunawan, 2003. Studi Karakteristik Volume Tabung Udara Dan Beban Katub Limbah.

Silla Charles, 2014. Pengaruh Diameter Tabung Udara Dan Jarak Lubang Pipa Tekan Dengan Katup Penghantar Terhadap Efisiensi Pompa Hydram. Jurusan Tehnik Mesin, Fakultas Sains Dan Tehnik Universitas Nusa Cendana.Terhadap Efisiensi Pompa Hydraulic Ram. Jurusan Teknik Mesin. Fakultas Teknologi Industri, Universitas Kristen Petra.

Subroto, Shodikin, 2015. Pengaruh Volume Tabung Tekan Terhadap Unjuk Kerja Pompa

Hidram, Teknik Mesin Universitas Muhammadiah Surakarta Jl. A. Yani Tramol Pos 1 Pabean, Kartasura.

Widarto, L. dan Sudarto, FX. (1997). Teknologi Tepat Guna Membuat Pompa Hidram. Kanisius: Yogyakarta. 